\title{
Economic energy management in textile industry using meta-heuristic algorithms incorporating solar distributed generation
}

\author{
Preetha. P. $\mathrm{S}^{\mathbf{1}^{*}}$ and Ashok Kusagur ${ }^{2}$ \\ Research Scholar, Department of Electrical and Electronics Engineering, Jain Institute of Technology, Davanagere- \\ 03, India ${ }^{1}$ \\ Associate Professor, Department of Electrical and Electronics Engineering, UBDT College of Engineering, \\ Davanagere-03, India ${ }^{2}$ \\ Received: 22-July-2021; Revised: 20-December-2021; Accepted: 22-December-2021 \\ (C)2021 Preetha.P. S and Ashok Kusagur. This is an open access article distributed under the Creative Commons Attribution (CC \\ BY) License, which permits unrestricted use, distribution, and reproduction in any medium, provided the original work is \\ properly cited.
}

\begin{abstract}
Among the various industrial businesses, the textile industry is one of the most energy-intensive. Energy cost reductions in these industries are one of the prime intentions of the industrialists. Energy Management System (EMS) gains importance with the increase in production and higher market space. Distribution Companies (DISCOMS) charge higher tariff while industries use power in the peak loading condition of the distribution system. This paper proposes a load scheduling method among the loads that are uninterrupted loads, fixed loads, and the shiftable loads. Optimization of load scheduling algorithm for minimizing the total energy cost is developed. Load scheduling using optimization algorithms like Genetic Algorithm (GA) and Particle Swarm Optimization (PSO) for lowest energy cost is developed. Analysis by adding the solar based power and finding the break-even point due to the introduction of a capital cost due to Photovoltaic (PV) installation. The proposed algorithm is applied with the energy tariff that is charged by the Bangalore Electricity Supply Company Limited (BESCOM) for different industrial loading levels. MATLAB based implementation of these optimization techniques is compared with the Bat algorithm for performance evaluation. Cost benefits of around $24.4 \%$ are evident from the cost analysis while $P V$ installation of $300 \mathrm{~kW}$ is incorporated in the textile industry premises. Break even for the industry because the PV installation will be obtained after 3.5 years.
\end{abstract}

\section{Keywords}

Particle swarm optimization (PSO), Bat algorithm, Genetic algorithm (GA), Energy management, Textile industry.

\section{Introduction}

Industries all over the world are becoming competitive with globalization and privatization entering the markets of every country. Energy conservation plays the pivotal role in the competitive environment. International laws on carbon imprint regulation also led to acceptance of better energy efficiency norms in the industries [1]. All these constraints have led to electricity conservation measures in the industry. The increase in a utility load causes stability problems and increases the cost of electricity. The power system is a complex structure that includes generation \& transmission. Thus, it does not allow power management at the transmission level of the power system. Power management at the utility level is possible with the lesser number of power transfer devices.

*Author for correspondence

1669
The industries, factories, hospitals, and malls can be operated in a well-defined scheduled manner due to its autonomous structure. Power scheduling inside the autonomous structure of power system can impact in the energy conservation.

India is the second largest producer of rice [2] and cotton [3]. A chunk of the power is used by both the rice and the textile industries. Every new load or new generation reckons a new power distribution plan. Change in the capacity of the feeder introduces further cost that involves changing new protection devices. Smart grids can interact with the load and other devices connected in the distributed power system. Advanced communication technology is used to realize the data flow between the grid and the load. Smart energy meters involved in the smart grid have the capability to communicate between the distribution grid and the other components in the 
power system [4]. Smart grid and smart energy meters can manage energy using the load and the generated data. Different load scheduling algorithms in the industry and academia are discussed in the following sections.

\section{Literature survey}

India is the largest cotton producing country in the world [5]. Textile industry contributes 2\% (20182019) of the gross domestic product of the country. Electricity cost contributes to $15-20 \%$ of the running cost of any textile industry [6]. Considering cheaper sources of energy and better energy management algorithms, keeps the industry in the competition. Renewable energy power generation is increased by $41 \%$ in 2020 [7]. To increase in the energy demand, the introduction of new generators and Renewable Energy Source (RES) is necessary. The incorporation or penetration of Distributed Generators (DGs) in the existing grid causes revamping the entire power system [8]. DGs and the distribution system controlled using smart devices, called the smart grid. Power system variables are measured using the smart metering system [9]. Management and demand forecasting in the smart grid implementation, can attain peak shaving [10] that reduces energy cost and improves stability. Smart grid implementation is selfhealing during peak loads [11]. Customers prefer to pay less for the energy used. Customers can pay less by shifting their time of energy usage during the nonpeak load. Technique to identify and utilize non-peak load schedules is developed [12]. Residential user's energy management technique that reduces the peak energy and optimizes energy cost for a better smart grid implementation is developed [13]. Energy management implementation can be defined as an optimization formulation. Meta-heuristic optimization and hybrid optimization algorithms obtain global optimal solution in any search based problem formulation [14-16]. Energy management algorithm schedules home utility reducing energy cost and Peak to Average Ratio (PAR) is developed. Genetic Algorithm (GA) is used to schedule the appliances in the smart home application [17]. Economic efficiency is defined as the ratio of total consumer benefits to electricity bill paid by the customer [18]. Load scheduling algorithm increasing customer's economic efficiency is developed using fractional programming approach. Economic efficiency analysis with Distributed Energy Resources (DERs) introduced in the distribution system is developed. Energy management with different meta-heuristic algorithms for both RES penetration and Energy Storage System (ESS) scenario is developed [19]. Economic load dispatch solution with Harmony search and Improved Harmony Search (IHS) algorithm is compared. Results indicate that IHS algorithm provided a better convergence and reduced fuel cost [20]. Importance of smart grid implementation of future energy security of the distribution system is presented [21]. A review on the importance of RES introduction in smart grid is discussed [22]. Demand Side Management (DSM) system is developed [23]. Customers are directed to take decisions on the day ahead energy consumption using Evolutionary Algorithm (EA) [23]. Both electrical and thermal loads are scheduled to reduce energy cost in a smart home automation environment. A choice for users to choose their energy usage strategy is provided [24]. Peak load shaving algorithm is developed using the Vehicle to Grid (V2G) and the ESS scenario. Load scheduling profile using the linear programming algorithm is developed [25]. Energy optimization algorithm is developed using mixed integer programming [26]. Versatile Convex Programming (CP) is used for demand response of the different appliances in the optimized load scheduling environment [27]. The Internet of Things (IoT) based algorithm is developed for energy management. Smart grid environment by fixing the maximum capacity for a consumer is developed [28]. Solar power integrated grid system with Electric Vehicle (EV) is managed for incentivized energy management by reducing the house loading in the day ahead load scheduling [29].

Incentive based Energy management system (EMS) in residential infrastructure is developed. Managing the usage of the residential user's electrical appliances is scheduled $[30,31]$. A noticeable reduction in peak power and energy cost is observed. Gaming strategy for peak power compensation in EVs and load compensation in rooftop solar power is developed [32]. Power Management Algorithm (PMA) in three different scenarios (with and without RES and ESS) is developed [33].

\subsection{Research problem}

Different peak shaving, load scheduling algorithms are developed in previous literatures. But, adoption of RES as a primary energy source in load scheduling paradigm is not incorporated. Since higher subsidies are provided by the Ministry of Renewable Energy (MNRE) Government of India [34], the usage of PV installation in the industry becomes economically beneficial. Indian textile industries can get benefitted from the PV installation. Cost benefit analysis in load 
scheduling algorithm with PV incorporation is a problem to be solved.

\subsection{Objectives}

Load scheduling algorithm with PV penetration of the power system is validated in the proposed implementation. Energy cost efficiency of the proposed load scheduling algorithm is analyzed. The breakeven point of the PV installation cost is inferred.

\subsection{Contribution}

This paper adopts the load scheduling algorithm that introduces the PV generated power as the primary energy source. Fixed load, shifting loads and uninterruptible load is scheduled. Energy cost is optimized by stochastically scheduling the load in the 24 hour schedule of the textile industry. The tariff profile of Bangalore Electricity Supply Company Limited (BESCOM) is applied for cost calculation.

Fixed load works in a fixed period of time which remains unchanged. Uninterruptible load operates uninterrupted through continuous period. But it is flexible in the 24-hour slot. Shiftable equipment uses energy at any time decided by the user. Textile industry equipment schedule [6] is used for the proposed formulation (equations (1) to (5)).

A scheduler scheduling equipment in the textile industry for economic operation is developed [23]. Load demand from the consumer and the pricing details of the utility, are communicated to both utility and the consumer by means of smart meters. The energy management controller receives data from both sides to schedule the energy delivery. Figure 1 depicts the basic architecture of an EMS system for an industry. This paper is an extension of the previous paper published by the author [35].

The ON state of the equipment is defined as ' 1 ' in the scheduling algorithm while the OFF state is defined as ' 0 '. EMS in Figure 1 schedules, load operating times controlled by smart meter input. Availability of PV energy is also added in the constraint for scheduling. PV energy available for any time in the day supplies the load power. Cost efficiency of load scheduling is a stochastic problem. Exploiting different meta-heuristic algorithms in the textile industry load scheduling algorithm results in economic implications. Appropriate algorithms that lead to energy cost reduction are evaluated by comparing bio-inspired algorithms.

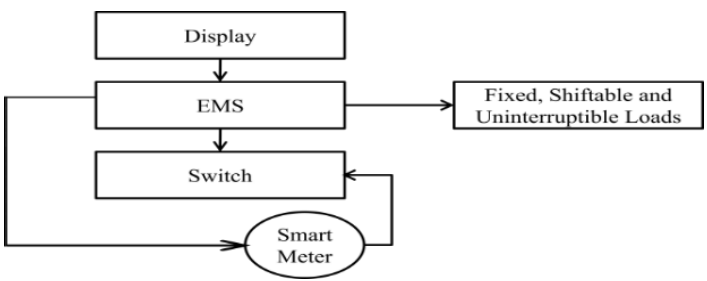

Figure 1 Proposed energy management system

\section{Methodology}

3.1Problem formulation

Proposed load scheduling formulation with energy cost optimization algorithm is discussed in this section.

\subsubsection{Fixed loads}

The load consumption for fixed loads is defined in equation (1). It is the sum of product of load demand for 24 hours cumulatively. ON/OFF state for fixed equipment is denoted as fa(t), where ' $t$ ' is the time slot $(\mathrm{t}=\{1,2, \ldots, 24\}) . \mathrm{U}(\mathrm{t})$ is the total load consumption for fixed loads. 'fa' is one equipment in the set of equipment's 'Fap' (Equation 1).

$\mathrm{U}(\mathrm{t})=\sum_{\mathrm{f}_{\mathrm{a}} \in \mathrm{F}_{\mathrm{ap}}}\left(\sum_{\mathrm{t}=1}^{24} \rho \mathrm{f}_{\mathrm{a}} \times \gamma \mathrm{f}_{\mathrm{a}}(\mathrm{t})\right.$

Where $\mathrm{a}=\{1,2, . . \mathrm{n}\}$ indicates the number of loads and $\mathrm{t}=\{1,2, \ldots \ldots, 24\}$ indicates hour of the day.

3.1.2Shiftable loads

Like the fixed load devices, the power consumption for the shiftable load devices is as given in equation (2). The term $V(t)$ indicates the power consumption of the shiftable load in the textile industry. $\gamma s_{a}(t)$ indicates the state of the loads whether it is "ON" or "OFF" (Equation 2).

$V(t)=\sum_{s_{a} \in S_{a p}}\left(\sum_{t=1}^{24} \rho s_{a} \times \gamma s_{a}(t)\right.$

$\rho s_{a}$ is the power of the shiftable load appliance in equation (2)

3.1.3Uninterruptible loads

Similarly, for the uninterruptible power load, the total power usage is as given in the equation (3). The term $\mathrm{W}(\mathrm{t})$ is the power consumption of the uninterruptible load in the textile industry (Equation 3 ).

$\mathrm{W}(\mathrm{t})=\sum_{\mathrm{ui}_{\mathrm{a}} \in \mathrm{UI}_{\mathrm{ap}}}\left(\sum_{\mathrm{t}=1}^{24} \rho \mathrm{ui}_{\mathrm{a}} \times \gamma \mathrm{ui}_{\mathrm{a}}(\mathrm{t})\right)$

The term $\rho \mathrm{i}_{\mathrm{a}}$ is the power consumables of uninterruptible load appliance in equation (3). $\gamma \mathrm{ui}_{\mathrm{a}}(\mathrm{t})$ indicates the state of the loads whether it is "ON" or "OFF".

\subsection{Energy consumption model}

Equation 4 defines the overall sum of all the power usage equations defined in Equation 1, 2 and 3. Overall energy consumption of the textile industry is defined as,

$\mathrm{P}_{\mathrm{T}}(\mathrm{t})=$

$\sum_{\mathrm{f}_{\mathrm{a}} \in \mathrm{F}_{\mathrm{ap}}}\left(\sum_{\mathrm{t}=1}^{24} \rho \mathrm{f}_{\mathrm{a}} \times \gamma \mathrm{f}_{\mathrm{a}}(\mathrm{t})+\right.$ 
$\sum_{\mathrm{s}_{\mathrm{a}} \in \mathrm{s}_{\mathrm{ap}}}\left(\sum_{\mathrm{t}=1}^{24} \rho \mathrm{s}_{\mathrm{a}} \times \gamma \mathrm{s}_{\mathrm{a}}(\mathrm{t})\right)+$

$\sum_{\mathrm{ui}_{\mathrm{a}} \in \mathrm{UI}_{\mathrm{ap}}}\left(\sum_{\mathrm{t}=1}^{24} \rho \mathrm{ui}_{\mathrm{a}} \times \gamma \mathrm{ui}_{\mathrm{a}}(\mathrm{t})\right)$

The overall energy consumption model is defined in Equation 4. Using the energy consumption, the total energy cost is calculated.

\subsection{Energy cost model}

From the energy consumption model defined in Equation 4, the energy cost model is developed that is defined in the Equation 5. The cost of the overall energy consumption model is,

$\mathrm{C}_{\mathrm{T}}=\sum_{\mathrm{t}=1}^{\mathrm{T}}\left(\mathrm{P}_{\mathrm{T}}(\mathrm{t}) \times \lambda(\mathrm{t})\right)$

The pricing profile for different timings is defined in the term $\lambda(\mathrm{t})$. Since the pricing of the power is variable for the normal and the peak loading conditions, the profile is defined for different timings. The problem thus formulated has generated the objective function as the cost function in equation (5). Stochastic nature of the uninterruptible and the shiftable loads are exploited by the meta-heuristic algorithms to economically schedule the loads.

\subsection{Solution methodology}

The area of optimization in different streams of engineering has a deep impact by meta-heuristic methods. The performance of these algorithms is of importance, because the hardware implementation of these algorithms is to be carried out for different engineering applications. Optimization of load scheduling for both shiftable and uninterruptible loads with three optimization algorithms is developed. The binary sequence that indicates the load ON and OFF position is generated that minimizes the energy cost defined in equation (5). Problem formulated is solved using Particle Swarm Optimization (PSO), GA, and Bat algorithm to obtain the optimal load scheduling in the textile industry [6]. 3.4.1Particle swarm optimization (PSO)

A bio-inspired meta-heuristic algorithm, PSO mathematically emulates the food searching behaviour of the flock of birds. Any optimization problem contains the dependent and independent variables for the search space. In the scheduling of loads, fixed load is not changing and it is fixed in the first four columns of the search space matrix developed. Since the search space does have first four columns with unchanged status due to fixed load, they are not allowed for random population in the meta-heuristic optimization. Rest of the columns in the search space is populated using the optimization algorithm for the cost minimization problem for the cost function defined in equation (5). Total number of 1672 populations generated randomly is 1000 . Number of equipment used is 16 , hours of operation are 24 hours and total number of populations generated is 1000 . Random generation of matrix of size $12 \times 24$ is generated for 1000 population. Value between ' 0 ' to ' 1000 ' is chosen as the search space. Among them firstly, some fifty values are chosen as the initial population. Then the velocity function is applied on the 50 population which defines the position of the matrix in the total 1000 populations. As per the PSO algorithm, the population is updated for all iteration and checked for convergence with the objective function defined in equation (5). Flowchart defined in Figure 2 is used to populate the position of the matrix in the list of random matrices generated. PSO parameter in the flowchart is the position of the random matrix generated which is populated in the iteration that follows. Uninterruptible load is used for the continuous time period. This continuous time of each of the Uninterruptible load is circularly shifted to obtain the new population, while the shiftable load is randomly generated in the populated matrices. As the initial population of 50 particles is generated, that is denoted as $X_{j}$ where $j=1,2 \ldots .50$. Updating these 50 particles for every iteration is calculated by finding the velocity values as given in Equation 6.

$$
\begin{aligned}
& V_{j}(i)=V_{j}(i-1)+c_{1} r_{1}\left[P_{\text {best } j}-X_{j}(i-1)\right]+ \\
& c_{2} r_{2}\left[G_{\text {best }}-X_{j}(i-1)\right]
\end{aligned}
$$

Where, $\mathrm{j}=1,2 \ldots \mathrm{N}$

Here, c1, c2 are cognitive and social learning rates taken as 2

$\mathrm{r} 1, \mathrm{r} 2$ are uniformly distributed random in range 0 and 1. After initialized particles are applied for the objective function for finding the best fit values, the particle is updated for the new set of particles as given in Equation 7. Velocity values generated from each iteration is updated using the Equation 6.

$X_{j}(i)=X_{j}(i-1)+V_{j}(i)$

Updated particle values generated from the Equation 7 is applied on the objective function for obtaining the new fitness value from the Equation 5.

\subsubsection{Genetic algorithm (GA)}

Genetic behaviour and its transition in human being are mathematically defined, so that it can be used for solving many scientific optimization problems. This method is called GA. The solution steps are given below in the Figure 3. 


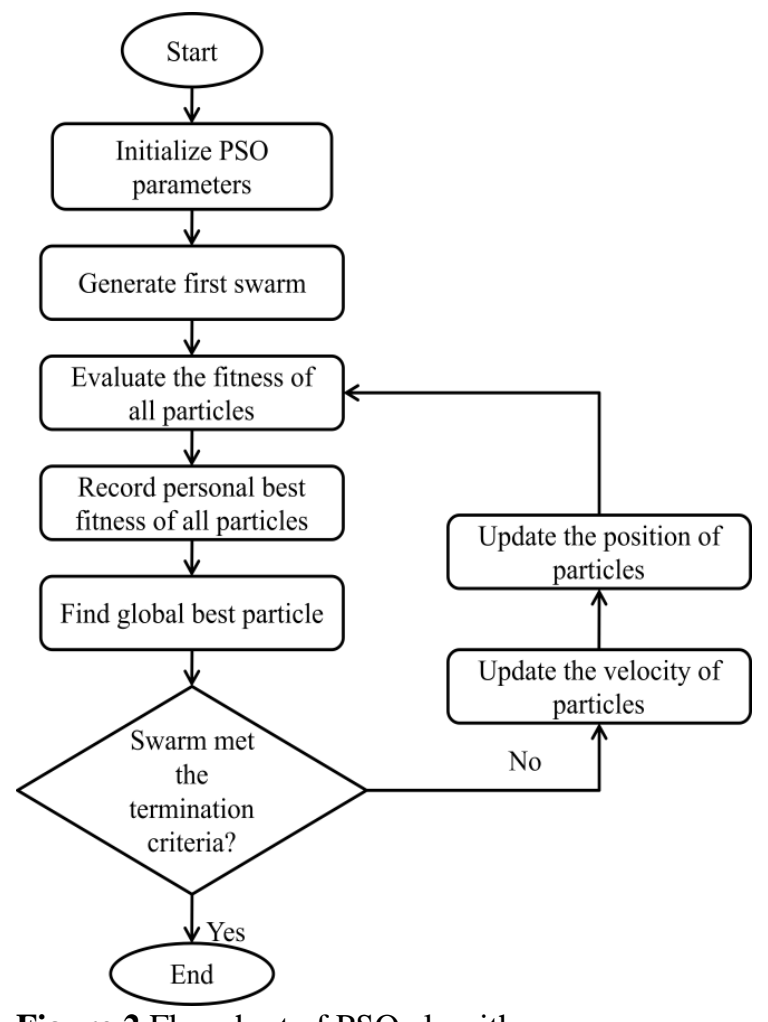

Figure 2 Flowchart of PSO algorithm

The GA implementation uses the same parameters as the PSO implementation detailed in the preceding section, while the particle update technique is defined [17].

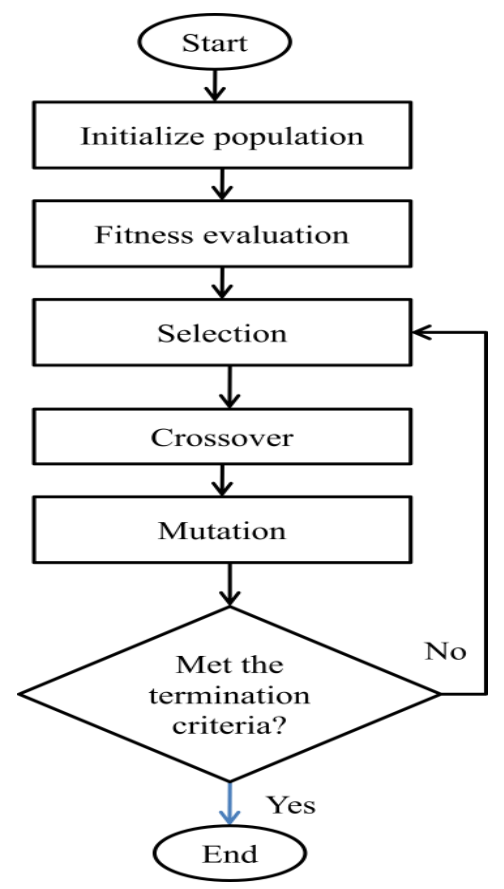

Figure 3 Flowchart of GA 1673

\subsubsection{Bat algorithm}

Bat's capability of echolocation that helps bats to discriminate among its prey, even in complete darkness is used mathematically in the algorithm [36]. Algorithm of meta-heuristic implementation is discussed in detail [37]. The flowchart of the Bat algorithm is defined in Figure 4.

All the three algorithms are applied on the problem defined in the formulation section to compare PSO, Bat algorithm and GA and the compared results are tabulated for the results and discussion is added to obtain the comparative analysis of different algorithms utilized in the implementation.

With the objective function as the energy cost minimization (equation (5)), meta-heuristic methods solve the load scheduling. MATLAB based simulation is developed to obtain the cost optimized energy management by scheduling different types of loads in the textile industry scenario. Software and hardware configurations used for the proposed implementation is as given in the Table 1 .

Table 1 Software and hardware configuration

\begin{tabular}{lll}
\hline \multicolumn{2}{l}{ Software configuration } & \multicolumn{2}{l}{ Hardware configuration } \\
\hline MATLAB 2017b in & I7 processor, $8 \mathrm{~GB}$ \\
Windows 10 & RAM,3.3GHz \\
Developed using M- files & \\
\hline
\end{tabular}

Results obtained by implementing the optimization for scheduling load in the textile industry for minimizing the cost is as given in the following section.

\section{Results and discussion}

Load data for all the three categories are obtained [6]. Energy tariff fixed by the Karnataka state in India is considered here for cost analysis. Electricity tariff plan defined by DISCOMS in Karnataka [29] is as given in Table 2. Hourly requirement of power by different categories of the load is considered [6]. While at the same time, the cost of energy which is flexible according to the total power usage is obtained from the tariff details [29] as shown in Table 2.

Table 2 Electricity tariff, Karnataka, India for industries

\begin{tabular}{ll}
\hline Time of day & Tariff \\
\hline $22.00 \mathrm{hrs}$ to $06.00 \mathrm{hrs}$ & $(-) 100$ paise per unit \\
\hline $06.00 \mathrm{hrs}$ to $10.00 \mathrm{hrs}$ & $(+) 100$ paise per unit \\
\hline $10.00 \mathrm{hrs}$ to $18.00 \mathrm{hrs}$ & 0 paise per unit \\
\hline $18.00 \mathrm{hrs}$ to $22.00 \mathrm{hrs}$ & $(+) 100$ paise per unit \\
\hline
\end{tabular}


Preetha.P. S and Ashok Kusagur

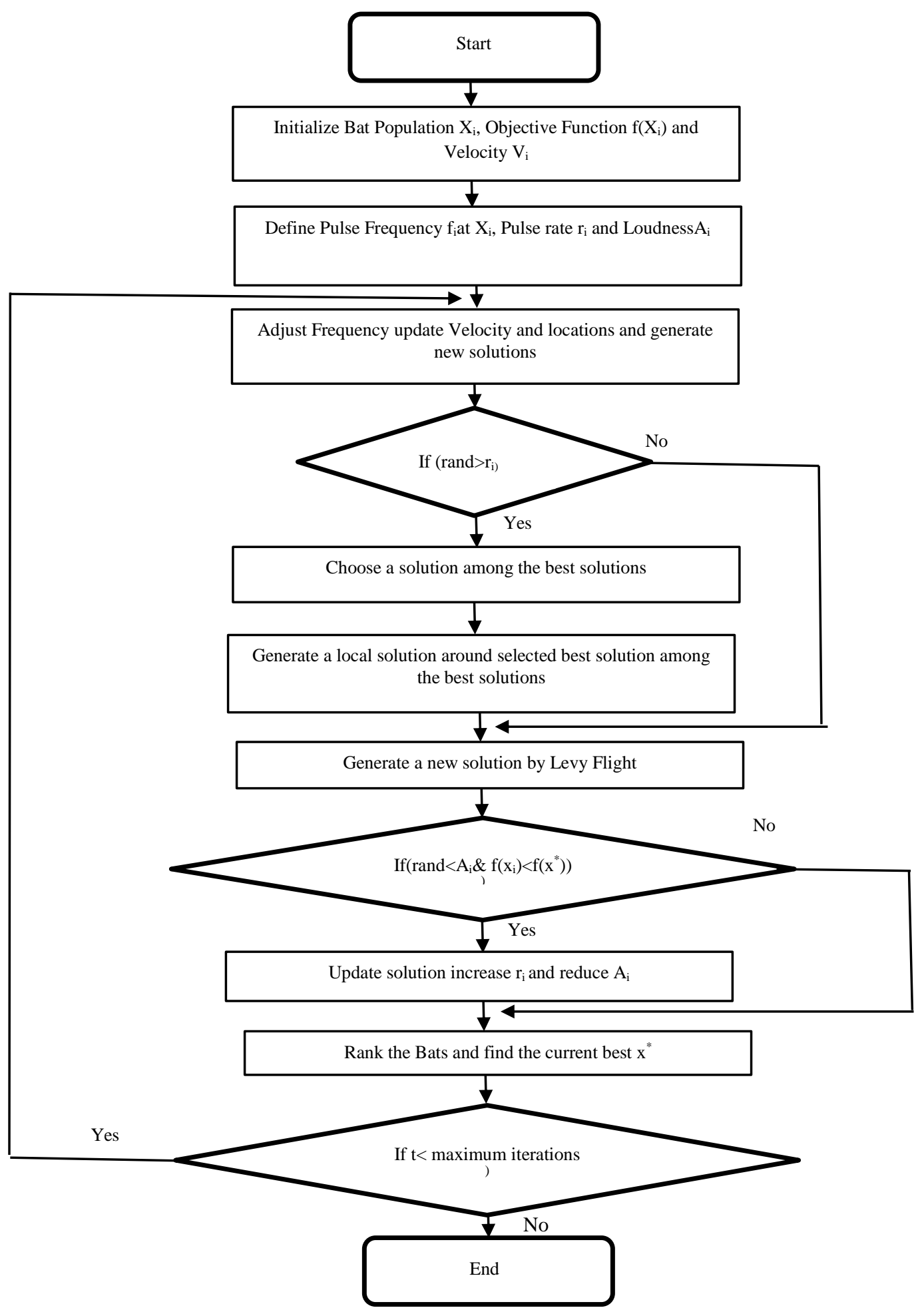

Figure 4 Flowchart of Bat algorithm 
The BESCOM's electricity tariff [29] with change in hours of operation is as shown in Figure 5. The cost calculated from the fitness function in the Equation 5 is taken from the graph as given in the Figure 5.

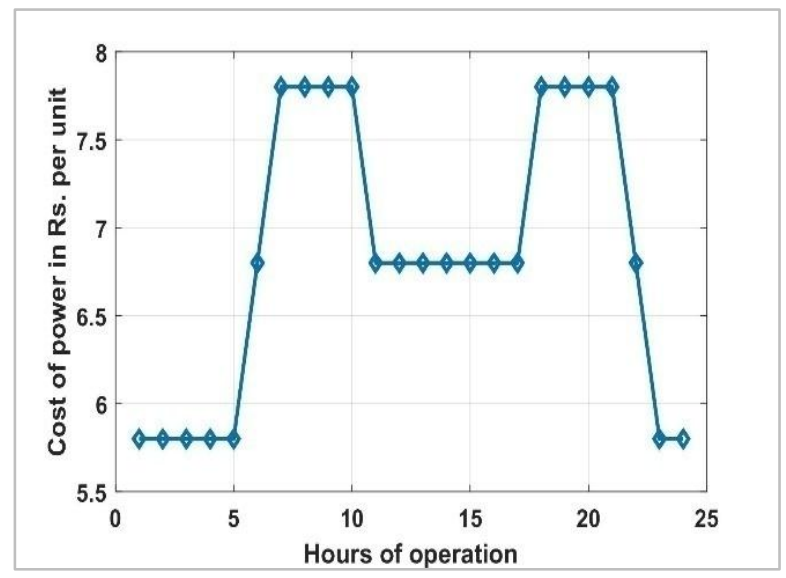

Figure 5 BESCOM electricity tariff

The Convergence graph for all the three algorithms is as shown in Figure 6. Cost in rupees versus the number of iterations is drawn for all the three algorithms. It can be observed from Figure 6 that the cost reduction due to load scheduling using the Bat algorithm is better optimized than the PSO and GA. Convergence graph that provides the fitness value obtained from the Equation 5 for every iteration is obtained. A convergence value for each iteration is plotted for all the three meta-heuristic algorithms as given in Figure 6. Energy cost from Equation 5 versus the number of iterations for each algorithm is plotted. Since cost minimization is the objective of the industrial load scheduling optimization for each iteration leads to a reduction in the cost. Convergence of each algorithm is observed while there is no change in the energy cost continuously for succeeding iterations. A convergence graph of the proposed implementation using the three algorithms shows that the PSO and GA algorithm used only 2 iterations to converge while Bat algorithm converged in 32 iterations. A convergence graph of the Bat algorithm is as shown in Figure 6 with the 'blue' plot. Observed convergence graph in Figure 6 clearly shows the domination of the Bat algorithm among the three algorithms. GA and PSO algorithms almost have a similar performance and while the Bat algorithm showing better results in the convergence performance. Convergence graph shows that both GA and PSO algorithms converged although the minimization is better pronounced in the Bat algorithm solution. Load scheduling output from the GA is as shown in Table 3. Since the first four equipment's are fixed loads the time scheduling of those equipments is fixed and not considered for optimized cost reduction. Optimized scheduling of each of the 16 loads considered from the total 20 loads is tabulated. Optimized scheduling for the GA algorithm is as given in the Table 3. Optimized scheduling of the load for total 24 hours is given which corresponds to the lowest energy cost.

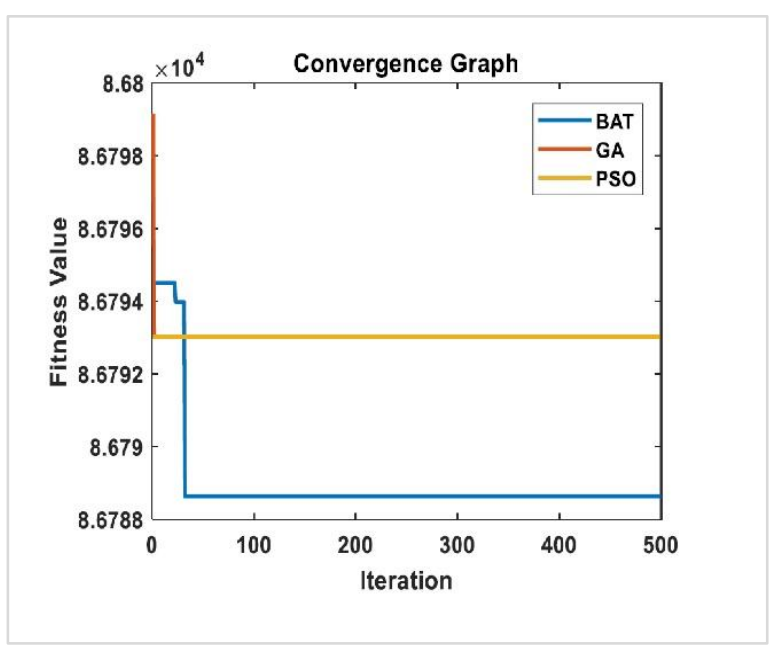

Figure 6 Compared cost function

A convergence graph of the PSO algorithm is as shown in Figure 6 with the 'yellow' plot. The load scheduling for the textile industry for a 24-hour period with PSO algorithm is tabulated in the Table 4.

Since the fixed loads uses a fixed time period in the operation hours for the first four equipment number and rest the equipment number are shiftable and uninterruptible load. Performance evaluation of these optimization algorithms with Bat algorithm and the non-optimal results is provided in Table 5 and Table 6 respectively. The load scheduling for the textile industry for a 24-hour period with non-optimal operation is tabulated in the Table 6. Optimized scheduling results in obtaining reduced cost for the cost function defined in Equation 5 is given in Table 7. To compare the non-optimized scheduling of load with the optimized scheduling of load and to compare the energy cost during these scenarios a nonoptimized scheduling scenario is also considered. Table 6 provides the non-optimized scheduling of load, and the corresponding energy cost is provided in the Table 7. Non optimized scheduling of load provides the highest cost. Lowest energy cost is obtained while scheduling the load using the Bat algorithm. 
Preetha.P. S and Ashok Kusagur

Table 3 Schedule of GA for shiftable and uninterruptable load

\begin{tabular}{|c|c|c|c|c|c|c|c|c|c|c|c|c|}
\hline \multirow[t]{2}{*}{ Hours } & \multicolumn{12}{|c|}{ Equipment number } \\
\hline & 5 & 6 & 7 & 8 & 9 & 10 & 11 & 12 & 13 & 14 & 15 & 16 \\
\hline 1 & 0 & 0 & 1 & 1 & 0 & 0 & 1 & 0 & 1 & 1 & 0 & 0 \\
\hline 2 & 0 & 0 & 0 & 0 & 0 & 0 & 0 & 0 & 1 & 0 & 1 & 0 \\
\hline 3 & 1 & 1 & 0 & 0 & 1 & 0 & 0 & 0 & 0 & 0 & 1 & 1 \\
\hline 4 & 1 & 1 & 0 & 0 & 1 & 0 & 0 & 0 & 0 & 0 & 0 & 0 \\
\hline 5 & 0 & 0 & 0 & 0 & 0 & 0 & 0 & 0 & 0 & 0 & 0 & 0 \\
\hline 6 & 0 & 0 & 0 & 0 & 1 & 0 & 0 & 0 & 0 & 0 & 0 & 0 \\
\hline 7 & 0 & 0 & 1 & 0 & 0 & 0 & 0 & 0 & 0 & 0 & 0 & 0 \\
\hline 8 & 0 & 0 & 0 & 0 & 0 & 0 & 0 & 0 & 0 & 0 & 0 & 0 \\
\hline 9 & 0 & 0 & 0 & 1 & 0 & 0 & 0 & 0 & 0 & 0 & 0 & 0 \\
\hline 10 & 0 & 0 & 0 & 1 & 0 & 0 & 0 & 0 & 0 & 0 & 0 & 0 \\
\hline 11 & 0 & 1 & 0 & 0 & 1 & 0 & 0 & 0 & 0 & 0 & 0 & 0 \\
\hline 12 & 1 & 0 & 0 & 1 & 0 & 0 & 0 & 0 & 0 & 0 & 0 & 0 \\
\hline 13 & 1 & 0 & 0 & 0 & 0 & 0 & 0 & 0 & 0 & 0 & 0 & 0 \\
\hline 14 & 0 & 0 & 0 & 0 & 1 & 0 & 0 & 0 & 0 & 0 & 0 & 0 \\
\hline 15 & 0 & 0 & 0 & 0 & 0 & 0 & 0 & 0 & 0 & 0 & 0 & 0 \\
\hline 16 & 1 & 0 & 1 & 1 & 1 & 0 & 0 & 0 & 0 & 0 & 0 & 0 \\
\hline 17 & 0 & 1 & 1 & 0 & 1 & 0 & 0 & 0 & 0 & 0 & 0 & 0 \\
\hline 18 & 1 & 0 & 0 & 0 & 0 & 0 & 0 & 0 & 0 & 0 & 0 & 0 \\
\hline 19 & 0 & 0 & 0 & 0 & 0 & 0 & 0 & 0 & 0 & 0 & 0 & 0 \\
\hline 20 & 0 & 1 & 0 & 0 & 0 & 0 & 0 & 0 & 0 & 0 & 0 & 0 \\
\hline 21 & 0 & 0 & 0 & 0 & 0 & 1 & 0 & 0 & 0 & 0 & 0 & 0 \\
\hline 22 & 0 & 0 & 1 & 1 & 0 & 1 & 1 & 0 & 0 & 0 & 0 & 0 \\
\hline 23 & 0 & 1 & 1 & 1 & 1 & 1 & 1 & 1 & 0 & 0 & 0 & 0 \\
\hline 24 & 0 & 0 & 0 & 0 & 1 & 0 & 1 & 0 & 1 & 0 & 0 & 0 \\
\hline
\end{tabular}

Table 4 Schedule of PSO for shiftable and uninterruptible load

\begin{tabular}{|c|c|c|c|c|c|c|c|c|c|c|c|c|}
\hline \multirow[t]{2}{*}{ Hours } & \multicolumn{12}{|c|}{ Equipment number } \\
\hline & 5 & 6 & 7 & 8 & 9 & 10 & 11 & 12 & 13 & 14 & 15 & 16 \\
\hline 1 & 0 & 0 & 1 & 1 & 0 & 0 & 1 & 0 & 1 & 1 & 0 & 0 \\
\hline 2 & 0 & 0 & 0 & 0 & 0 & 0 & 0 & 0 & 1 & 0 & 1 & 0 \\
\hline 3 & 1 & 1 & 0 & 0 & 1 & 0 & 0 & 0 & 0 & 0 & 1 & 1 \\
\hline 4 & 1 & 1 & 0 & 0 & 1 & 0 & 0 & 0 & 0 & 0 & 0 & 0 \\
\hline 5 & 0 & 0 & 0 & 0 & 0 & 0 & 0 & 0 & 0 & 0 & 0 & 0 \\
\hline 6 & 0 & 0 & 0 & 0 & 1 & 0 & 0 & 0 & 0 & 0 & 0 & 0 \\
\hline 7 & 0 & 0 & 1 & 0 & 0 & 0 & 0 & 0 & 0 & 0 & 0 & 0 \\
\hline 8 & 0 & 0 & 0 & 0 & 0 & 0 & 0 & 0 & 0 & 0 & 0 & 0 \\
\hline 9 & 0 & 0 & 0 & 1 & 0 & 0 & 0 & 0 & 0 & 0 & 0 & 0 \\
\hline 10 & 0 & 0 & 0 & 1 & 0 & 0 & 0 & 0 & 0 & 0 & 0 & 0 \\
\hline 11 & 0 & 1 & 0 & 0 & 1 & 0 & 0 & 0 & 0 & 0 & 0 & 0 \\
\hline 12 & 1 & 0 & 0 & 1 & 0 & 0 & 0 & 0 & 0 & 0 & 0 & 0 \\
\hline 13 & 1 & 0 & 0 & 0 & 0 & 0 & 0 & 0 & 0 & 0 & 0 & 0 \\
\hline 14 & 0 & 0 & 0 & 0 & 1 & 0 & 0 & 0 & 0 & 0 & 0 & 0 \\
\hline 15 & 0 & 0 & 0 & 0 & 0 & 0 & 0 & 0 & 0 & 0 & 0 & 0 \\
\hline 16 & 1 & 0 & 1 & 1 & 1 & 0 & 0 & 0 & 0 & 0 & 0 & 0 \\
\hline 17 & 0 & 1 & 1 & 0 & 1 & 0 & 0 & 0 & 0 & 0 & 0 & 0 \\
\hline 18 & 1 & 0 & 0 & 0 & 0 & 0 & 0 & 0 & 0 & 0 & 0 & 0 \\
\hline 19 & 0 & 0 & 0 & 0 & 0 & 0 & 0 & 0 & 0 & 0 & 0 & 0 \\
\hline 20 & 0 & 1 & 0 & 0 & 0 & 0 & 0 & 0 & 0 & 0 & 0 & 0 \\
\hline 21 & 0 & 0 & 0 & 0 & 0 & 1 & 0 & 0 & 0 & 0 & 0 & 0 \\
\hline 22 & 0 & 0 & 1 & 1 & 0 & 1 & 1 & 0 & 0 & 0 & 0 & 0 \\
\hline 23 & 0 & 1 & 1 & 1 & 1 & 1 & 1 & 1 & 0 & 0 & 0 & 0 \\
\hline 24 & 0 & 0 & 0 & 0 & 1 & 0 & 1 & 0 & 1 & 0 & 0 & 0 \\
\hline
\end{tabular}


Table 5 Schedule of Bat for shiftable and uninterruptable load

\begin{tabular}{|c|c|c|c|c|c|c|c|c|c|c|c|c|}
\hline \multirow[t]{2}{*}{ Hours } & \multicolumn{12}{|c|}{ Equipment number } \\
\hline & 5 & 6 & 7 & 8 & 9 & 10 & 11 & 12 & 13 & 14 & 15 & 16 \\
\hline 1 & 0 & 1 & 0 & 0 & 0 & 1 & 1 & 0 & 0 & 0 & 0 & 0 \\
\hline 2 & 0 & 1 & 1 & 1 & 0 & 1 & 1 & 1 & 0 & 0 & 0 & 0 \\
\hline 3 & 0 & 1 & 0 & 1 & 1 & 0 & 1 & 0 & 1 & 0 & 0 & 0 \\
\hline 4 & 1 & 0 & 0 & 0 & 0 & 0 & 1 & 0 & 1 & 1 & 0 & 0 \\
\hline 5 & 0 & 0 & 1 & 1 & 1 & 0 & 0 & 0 & 1 & 0 & 1 & 0 \\
\hline 6 & 1 & 0 & 1 & 0 & 1 & 0 & 0 & 0 & 0 & 0 & 1 & 1 \\
\hline 7 & 0 & 0 & 0 & 0 & 0 & 0 & 0 & 0 & 0 & 0 & 0 & 0 \\
\hline 8 & 0 & 0 & 1 & 0 & 0 & 0 & 0 & 0 & 0 & 0 & 0 & 0 \\
\hline 9 & 1 & 0 & 0 & 0 & 0 & 0 & 0 & 0 & 0 & 0 & 0 & 0 \\
\hline 10 & 0 & 0 & 0 & 0 & 1 & 0 & 0 & 0 & 0 & 0 & 0 & 0 \\
\hline 11 & 0 & 0 & 0 & 0 & 1 & 0 & 0 & 0 & 0 & 0 & 0 & 0 \\
\hline 12 & 0 & 0 & 0 & 0 & 1 & 0 & 0 & 0 & 0 & 0 & 0 & 0 \\
\hline 13 & 1 & 0 & 1 & 0 & 0 & 0 & 0 & 0 & 0 & 0 & 0 & 0 \\
\hline 14 & 1 & 0 & 0 & 0 & 0 & 0 & 0 & 0 & 0 & 0 & 0 & 0 \\
\hline 15 & 0 & 0 & 0 & 1 & 0 & 0 & 0 & 0 & 0 & 0 & 0 & 0 \\
\hline 16 & 0 & 0 & 1 & 0 & 1 & 0 & 0 & 0 & 0 & 0 & 0 & 0 \\
\hline 17 & 0 & 0 & 0 & 0 & 0 & 0 & 0 & 0 & 0 & 0 & 0 & 0 \\
\hline 18 & 0 & 0 & 0 & 1 & 0 & 0 & 0 & 0 & 0 & 0 & 0 & 0 \\
\hline 19 & 0 & 0 & 0 & 1 & 0 & 0 & 0 & 0 & 0 & 0 & 0 & 0 \\
\hline 20 & 0 & 1 & 0 & 0 & 0 & 0 & 0 & 0 & 0 & 0 & 0 & 0 \\
\hline 21 & 0 & 0 & 0 & 0 & 0 & 0 & 0 & 0 & 0 & 0 & 0 & 0 \\
\hline 22 & 1 & 0 & 0 & 0 & 1 & 0 & 0 & 0 & 0 & 0 & 0 & 0 \\
\hline 23 & 0 & 1 & 0 & 0 & 1 & 0 & 0 & 0 & 0 & 0 & 0 & 0 \\
\hline 24 & 0 & 1 & 0 & 1 & 0 & 1 & 0 & 0 & 0 & 0 & 0 & 0 \\
\hline
\end{tabular}

Table 6 Schedule of non-optimal operation

\begin{tabular}{|c|c|c|c|c|c|c|c|c|c|c|c|c|c|c|c|c|}
\hline \multirow[t]{2}{*}{ Hours } & \multicolumn{16}{|c|}{ Equipment number } \\
\hline & 1 & 2 & 3 & 4 & 5 & 6 & 7 & 8 & 9 & 10 & 11 & 12 & 13 & 14 & 15 & 16 \\
\hline 1 & 0 & 0 & 0 & 0 & 0 & 0 & 0 & 0 & 0 & 0 & 0 & 0 & 0 & 0 & 0 & 0 \\
\hline 2 & 0 & 0 & 0 & 0 & 0 & 0 & 0 & 0 & 0 & 0 & 0 & 0 & 0 & 0 & 0 & 0 \\
\hline 3 & 0 & 0 & 0 & 0 & 0 & 0 & 0 & 0 & 0 & 0 & 0 & 0 & 0 & 0 & 0 & 0 \\
\hline 4 & 0 & 0 & 0 & 0 & 0 & 0 & 0 & 0 & 0 & 0 & 0 & 0 & 0 & 0 & 0 & 0 \\
\hline 5 & 0 & 0 & 0 & 0 & 0 & 0 & 0 & 0 & 0 & 0 & 0 & 0 & 0 & 0 & 0 & 0 \\
\hline 6 & 0 & 0 & 0 & 0 & 0 & 0 & 0 & 0 & 0 & 0 & 0 & 0 & 0 & 0 & 0 & 0 \\
\hline 7 & 0 & 0 & 0 & 0 & 0 & 0 & 0 & 0 & 0 & 0 & 0 & 0 & 0 & 0 & 0 & 0 \\
\hline 8 & 1 & 0 & 0 & 0 & 0 & 0 & 0 & 0 & 0 & 0 & 0 & 0 & 0 & 0 & 0 & 0 \\
\hline 9 & 1 & 0 & 0 & 0 & 0 & 0 & 0 & 0 & 0 & 0 & 0 & 0 & 0 & 0 & 0 & 0 \\
\hline 10 & 1 & 0 & 0 & 0 & 0 & 0 & 0 & 0 & 0 & 0 & 0 & 0 & 0 & 0 & 0 & 0 \\
\hline 11 & 1 & 0 & 0 & 0 & 0 & 0 & 0 & 0 & 0 & 0 & 0 & 0 & 0 & 0 & 0 & 0 \\
\hline 12 & 1 & 0 & 0 & 0 & 0 & 0 & 0 & 0 & 0 & 0 & 0 & 0 & 0 & 0 & 0 & 0 \\
\hline 13 & 1 & 0 & 0 & 0 & 0 & 0 & 0 & 0 & 0 & 0 & 0 & 0 & 0 & 0 & 0 & 0 \\
\hline 14 & 1 & 0 & 0 & 0 & 0 & 0 & 0 & 0 & 0 & 0 & 0 & 0 & 0 & 0 & 0 & 0 \\
\hline 15 & 1 & 0 & 0 & 0 & 0 & 0 & 0 & 0 & 0 & 0 & 0 & 0 & 0 & 0 & 0 & 0 \\
\hline 16 & 1 & 1 & 1 & 1 & 1 & 1 & 1 & 1 & 1 & 1 & 1 & 1 & 1 & 1 & 1 & 1 \\
\hline 17 & 1 & 1 & 1 & 1 & 1 & 1 & 1 & 1 & 1 & 1 & 1 & 0 & 1 & 0 & 1 & 0 \\
\hline 18 & 1 & 0 & 1 & 1 & 1 & 1 & 1 & 1 & 1 & 1 & 1 & 0 & 1 & 0 & 0 & 0 \\
\hline 19 & 0 & 0 & 0 & 0 & 1 & 1 & 1 & 1 & 1 & 0 & 1 & 0 & 0 & 0 & 0 & 0 \\
\hline 20 & 0 & 0 & 0 & 0 & 1 & 1 & 1 & 1 & 1 & 0 & 0 & 0 & 0 & 0 & 0 & 0 \\
\hline 21 & 0 & 0 & 0 & 0 & 1 & 1 & 1 & 1 & 1 & 0 & 0 & 0 & 0 & 0 & 0 & 0 \\
\hline 22 & 0 & 0 & 0 & 0 & 0 & 0 & 0 & 1 & 1 & 0 & 0 & 0 & 0 & 0 & 0 & 0 \\
\hline 23 & 0 & 0 & 0 & 0 & 0 & 0 & 0 & 0 & 1 & 0 & 0 & 0 & 0 & 0 & 0 & 0 \\
\hline 24 & 0 & 0 & 0 & 0 & 0 & 0 & 0 & 0 & 1 & 0 & 0 & 0 & 0 & 0 & 0 & 0 \\
\hline
\end{tabular}

The cost obtained from the Bat algorithm is found to be the optimized cost whereas the time taken for the solution is also better in Bat algorithm. Comparison 1677 of introducing the PV and not introducing PV in the optimizing algorithm is evident in Table 7. And execution time for each of the algorithms to converge 
and obtain the load scheduling output is also given in Table 7. PV power penetration in the Bat algorithm has shown a better reduction in the cost as the availability of the PV power helps in peak shaving. Thus, only the break-even point for the PV power generation must be taken carefully.

Hourly PV power variation available for the analysis is as shown in Figure 7. The amount of power generated from the PV is variable. These dynamics of power generation variation from the PV generator are considered for load scheduling.

Time taken for the execution of each algorithm with 500 iterations is as given in the Table 7.

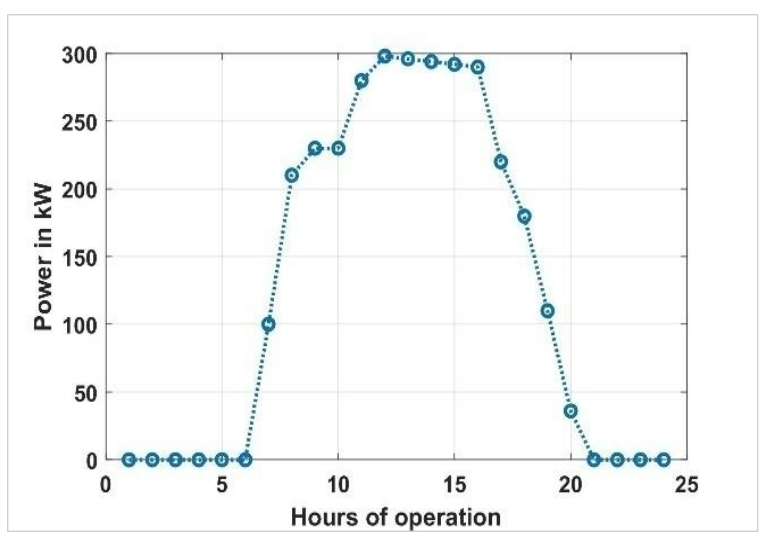

Figure 7 The PV power available hours on the premises in a day

Table 7 GA, PSO and Bat compared with non-optimal operation of the industry

\begin{tabular}{llll}
\hline PV connection of $300 \mathbf{~ k W}$ & Algorithms & Cost in Rs. & Time in sec \\
\hline without PV & Non-optimal operation & 86884 & - \\
\cline { 2 - 4 } & GA & 86793 & 43.06 \\
\cline { 2 - 4 } & PSO & 86793 & 42.23 \\
\cline { 2 - 4 } & Bat & 86789 & 20.34 \\
\hline With PV & Bat & 64844 & 20.34 \\
\hline
\end{tabular}

It is seen that the Bat performs well as it gives lesser cost and schedules differently compared to GA and PSO. Among GA and PSO, the PSO takes less time to achieve results, even though the Bat gives best scheduling. There is a difference of Rs. 95/day when compared to the non-optimal operation. If it is operated for 25 days in a month, it can save Rs. 2375/-and for a year, Rs. 28500/-can be saved. The electricity cost savings can be increased from Rs.95/day to Rs.22040/day by installing $300 \mathrm{~kW} \mathrm{PV}$ powerful in the industry. For installation of PV power needed the cost of the investment. The cost of the investment is taken [30]. Break even for the PV installation cost will be obtained after 3.5 years. Calculation in Table 8 clearly mentions that the break-even is possible in four years down the lane.

Table 8 Calculation of benefit to the industry after implementing PV power plant

\begin{tabular}{ll}
\hline Calculation definition & Parameters \\
\hline Total power required & $300 \mathrm{~kW}$ \\
\hline Cost of PV per kW in Rs. & $95,000.00$ \\
& {$[36]$} \\
\hline Total cost of investment required in Rs. & $28,500,000.0$ \\
& 0 \\
\hline Benefit per day in Rs. & $22,040.00$ \\
\hline To cover the cost of investment in days & $1,293.10$ \\
\hline Period of repay in years & 3.54 \\
\hline PV panel lifetime in years & 20.00 \\
\hline Years of free electricity from PV in years & 16.46 \\
\hline Total cost benefits per year after 3.5 years in & $8,044,600.00$ \\
Rs. & \\
\hline 1678 &
\end{tabular}

\subsection{Summary of key findings}

Cost benefits of around $24.4 \%$ are evident from the cost analysis while PV installation of $300 \mathrm{~kW}$ is incorporated in the textile industry premises. The breakeven point obtained for 4 years is found promising. PV installation in the textile industry with the better load scheduling provides a better cost advantage for the energy spending in the industry. Capital cost invested in the PV installation is also bound to be regained within 3.5 years of PV usage in the textile industry. A complete list of abbreviations is shown in Appendix $I$.

\subsection{Limitation of the proposed work}

Proposed implementation has the following limitation.

a. Proposed implementation uses sophisticated algorithms that increase the dependency on experts.

b. For any change in loading strategy or the introduction of new leads and renewable resource as power source needs changes in the software to obtain a better load scheduling.

c. Bat algorithm convergence needs thirty-two iterations to get the optimized load scheduling, but PSO and GA attained convergence in two iterations. 


\section{Conclusion and future work}

Energy management system using the load scheduling algorithm with a cost minimization optimization algorithm is developed using MATLAB simulation. The tariff profile of the BESCOM, a DISCOMS company based in Karnataka, India is adopted for the cost minimization problem. Textile industry, thus taken for the energy management system is applied with three optimization algorithm GA, PSO and Bat algorithms. PV penetration and without PV penetration is compared to find that PV penetration in the textile industry has performed well with the Bat algorithm and there is a possibility of break-even point in four years to regain the PV installation costs. Scheduling algorithm is found to be effective for all kinds of loads in the textile industry. Economic load scheduling of the textile industry is developed using the meta-heuristic method with and without PV inclusion with three different metaheuristic algorithms and found that the results are satisfactory. PV installation in the textile industry with the better load scheduling provides a better cost advantage for the energy spending in the industry.

\section{Future Scope}

Penetration of different RES can be introduced in the Energy management system and analyzed for energy cost advantage with different RES. The real time variation of RES in the distribution system can be considered to develop the energy management system to get a better load scheduling for textile industry.

\section{Acknowledgment}

None.

\section{Conflicts of interest}

The authors have no conflicts of interest to declare.

\section{References}

[1] https://www.unep.org/. Accessed 22 October 2021.

[2] https://www.statista.com/statistics/255945/topcountries-of-destination-for-us-rice-exports-2011/. Accessed 22 October 2021.

[3] https://www.statista.com/statistics/797627/raw-cottonproduction-india/. Accessed 22 October 2021.

[4] Agnetis A, De PG, Detti P, Vicino A. Load scheduling for household energy consumption optimization. IEEE Transactions on Smart Grid. 2013; 4(4):2364-73.

[5] https://www.worldatlas.com/articles/top-cottonproducing-countries-intheworld.html\#: :text=Top\%20Cotton\%20Producing $\% 20$ Countries $\% 20$ In $\% 20$ The $\% 20$ World $\% 20, \% 20 \% 20$ $2 \% 2 \mathrm{C} 787 \% 20 \% 206 \% 20$ more\%20rows $\% 20$. Accessed 22 October 2021.
[6] Dhayaneswaran Y, Ashokkumar L. A study on energy conservation in textile industry. Journal of the Institution of Engineers (India): Series B. 2013; 94(1):53-60.

[7] http://www.nexans.com/Corporate/2010/WHITEPAPERSMART-GRIDS-(2010).pdf. Accessed 31 January 2021.

[8] Guo Y, Pan M, Fang Y. Optimal power management of residential customers in the smart grid. IEEE Transactions on Parallel and Distributed Systems. 2012; 23(9):1593-606.

[9] Nilsson $H$. The many faces of demand-side management. Power Engineering Journal. 1994; 8(5):207-10.

[10] Nalbalwar SL, Ruikar JD, Sakpal SR. Smart grid: a modernization of existing power grid. International Journal of Advanced Engineering Research and Studies. 2012; 1:295-8.

[11] Liu Y, Yuen C, Huang S, Hassan NU, Wang X, Xie S. Peak-to-average ratio constrained demand-side management with consumer's preference in residential smart grid. IEEE Journal of Selected Topics in Signal Processing. 2014; 8(6):1084-97.

[12] Patel K, Khosla A. Home energy management systems in future smart grid networks: a systematic review. In $1 \mathrm{st}$ international conference on next generation computing technologies 2015 (pp. 479-83). IEEE.

[13] Bao Z, Zhou Y, Li L, Ma M. A hybrid global optimization algorithm based on wind driven optimization and differential evolution. Mathematical Problems in Engineering. 2015.

[14] Rahim S, Javaid N, Ahmad A, Khan SA, Khan ZA, Alrajeh N, et al. Exploiting heuristic algorithms to efficiently utilize energy management controllers with renewable energy sources. Energy and Buildings. 2016; 129:452-70.

[15] Arafa M, Sallam EA, Fahmy MM. An enhanced differential evolution optimization algorithm. In fourth international conference on digital information and communication technology and its applications 2014 (pp. 216-25). IEEE.

[16] Rasheed MB, Javaid N, Awais M, Khan ZA, Qasim U, Alrajeh N, et al. Real time information based energy management using customer preferences and dynamic pricing in smart homes. Energies. 2016; 9(7):1-30.

[17] Ma J, Chen HH, Song L, Li Y. Residential load scheduling in smart grid: a cost efficiency perspective. IEEE Transactions on Smart Grid. 2015; 7(2):771-84.

[18] Ahmad A, Khan A, Javaid N, Hussain HM, Abdul W, Almogren A, et al. An optimized home energy management system with integrated renewable energy and storage resources. Energies. 2017; 10(4):1-35.

[19] Karthigeyan P, Raja MS, Hariharan R, Prakash S, Delibabu S, Gnanaselvam R. Comparison of harmony search algorithm, improved harmony search algorithm with biogeography based optimization algorithm for solving constrained economic load dispatch problems. Procedia Technology. 2015; 21:611-8.

[20] Islam MA, Hasanuzzaman M, Rahim NA, Nahar A, Hosenuzzaman M. Global renewable energy-based 
electricity generation and smart grid system for energy security. The Scientific World Journal. 2014.

[21] Phuangpornpitak N, Tia S. Opportunities and challenges of integrating renewable energy in smart grid system. Energy Procedia. 2013; 34:282-90.

[22] Logenthiran T, Srinivasan D, Shun TZ. Demand side management in smart grid using heuristic optimization. IEEE Transactions on Smart Grid. 2012; 3(3):1244-52.

[23] Shirazi E, Jadid S. Optimal residential appliance scheduling under dynamic pricing scheme via HEMDAS. Energy and Buildings. 2015; 93:40-9.

[24] Lee JY, Choi SG. Linear programming based hourly peak load shaving method at home area. In international conference on advanced communication technology 2014 (pp. 310-3). IEEE.

[25] Hubert T, Grijalva S. Realizing smart grid benefits requires energy optimization algorithms at residential level. In ISGT 2011 (pp. 1-8). IEEE.

[26] Tsui KM, Chan SC. Demand response optimization for smart home scheduling under real-time pricing. IEEE Transactions on Smart Grid. 2012; 3(4):181221.

[27] Kazmi S, Javaid N, Mughal MJ, Akbar M, Ahmed SH, Alrajeh N. Towards optimization of metaheuristic algorithms for IoT enabled smart homes targeting balanced demand and supply of energy. IEEE Access. 2017; 7:24267-81.

[28] https://bescom.karnataka.gov.in/storage/pdffiles/Customer\%20Relations/EXISITING-ANDREVISED-TARIFF-FOR-2019.xlsx. Accessed 22 October 2021.

[29] Li Z, Wang X, Lin D, Zheng R, Han B, Li G. Smart energy management model for households considering incentive-based demand response. In power system and green energy conference (PSGEC) 2021 (pp. 32732). IEEE.

[30] Zhang YW. Energy-aware non-preemptive scheduling of mixed-criticality real-time task systems. IEEE Transactions on Computer-Aided Design of Integrated Circuits and Systems. 2021.

[31] Kandpal B, Verma A. Demand peak reduction of smart buildings using feedback-based real-time scheduling of EVs. IEEE Systems Journal. 2021.

[32] Rashid MM, Hossain MA, Shah R, Alam MS, Karmaker AK, Rahman M. An improved energy and cost minimization scheme for home energy management (HEM) in the smart grid framework. In international conference on applied superconductivity and electromagnetic devices 2020 (pp. 1-2). IEEE.

[33] https://www.mnre.gov.in/solar/schemes/. Accessed 22 October 2021.

[34] Preetha PS, Kusagur A. Implementation of ant-lion optimization algorithm in energy management problem and comparison. In advances in decision sciences, image processing, security and computer vision 2020 (pp. 462-9). Springer, Cham.
[35] Yang XS, Gandomi AH. Bat algorithm: a novel approach for global engineering optimization. Engineering Computations. 2012; 29(5): 464-83.

[36] https://www.loomsolar.com/. Accessed 22 October 2021.

[37] Manjunath TG, Kusagur A. Analysis of different meta heuristics method in intelligent fault detection of multilevel inverter with photovoltaic power generation source. International Journal of Power Electronics and Drive Systems. 2018; 9(3):1214-22.

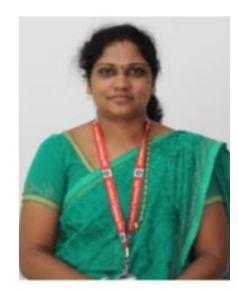

Preetha. P. S. was born in the year 1987 and she got her UG degree in Electrical \& Electronics Engg. from UBDTCE, Davanagere, Karnataka, India from Kuvempu University in 2008 and PG Degree in Power system \& power Electronics from UBDTCE, Davanagere, Karnataka, India from Kuvempu University in 2010. She has got an experience of 11 years in the teaching field. Presently, she is serving as Assistant Professor in the Department of Electrical \& Electronics Engineering, Jain Institute of Technology, Davanagere, Karnataka, India \& doing her Ph.D. (Research Scholar) in Electrical \& Electronics Engineering from Visvesvaraya Technological University, Belagavi, Karnataka, India. Her area of interests are Artificial Intelligence, Energy Management, Metaheuristic Approach, Neural Networks etc.

Email: ps.preetha@gmail.com

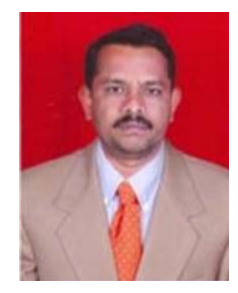

Dr. Ashok Kusagur was born in the year 1970 and he got his UG degree in Electrical \& Electronics Enginerring from Bapuji Institute of Enginerring \& Technology Davanagere, Karnataka,India from Kuvempu University in 1996 and PG Degree in Power Electronics from PDA College of Engineering, Gulbarga, Karnataka, India from VTU in 2001. He received his Ph.D. Degree in Electrical \& Electronics Engineering From Jawaharlal Nehru Technological University (JNTU), Hyderabad, Andra Pradesh, India in 2012. He has got an experience of 22 years in the teaching field. Presently, he is serving as Associate Professor and Training \& Placement Oficer in Dept. of Electrical \& Electronics Engineering, UBDTCE, Davanagere, Karnataka, India. He has got more than 90 research paper's publication in national, international journals \& conferences. He has also delivered a number of guest lectures \&seminars, workshops, symposiums in different institutions. A number of research scholars are perceiving Ph.D. under his guidance and 5 students got awarded. His area of interests are Neural Networks, Fuzzy Logic, Power Electronics etc.

Email: ashok.kusagur@gmail.com 


\begin{tabular}{lll}
\multicolumn{2}{l}{ Appendix I } \\
\hline S. No. & Abbreviation & Description \\
\hline 1 & BESCOM & $\begin{array}{l}\text { Bangalore Electricity Supply } \\
\text { Company Limited }\end{array}$ \\
\hline 2 & CP & Convex Programming \\
\hline 3 & DERs & Distributed Energy Resources \\
\hline 4 & DGs & Distributed Generators \\
\hline 5 & DISCOMS & Distribution Companies \\
\hline 6 & DSM & Demand Side Management \\
\hline 7 & EA & Evolutionary Algorithm \\
\hline 8 & EMS & Energy Management System \\
\hline 9 & ESS & Energy Storage System \\
\hline 10 & EV & Electric vehicle \\
\hline 11 & GA & Genetic Algorithm \\
\hline 12 & HIS & Improved Harmony Search \\
\hline 13 & IoT & The Internet of Things \\
\hline 14 & MNRE & Ministry of Renewable Energy \\
\hline 15 & PAR & Peak to Average Ratio \\
\hline 16 & PMA & Power Management Algorithm \\
\hline 17 & PSO & Particle Swarm Optimization \\
\hline 18 & PV & Photovoltaic \\
\hline 19 & RES & Renewable Energy Sources \\
\hline 20 & V2G & Vehicle to Grid \\
\hline
\end{tabular}

